\title{
Special issue "Crustal dynamics: toward integrated view of island arc seismogenesis"
}

\author{
Toru Matsuzawa ${ }^{1 *}$, Ichiko Shimizu ${ }^{2}$, Takuya Nishimura ${ }^{3}$, Christopher J. Spiers ${ }^{4}$, Junichi Nakajima ${ }^{5}$ \\ and Tatsuhiko Kawamoto ${ }^{6}$
}

Recent deployments of dense seismic and geodetic observation networks have revealed a detailed pattern of crustal stress and strain rate in tectonically active regions all over the world. Furthermore, the 2011 M9.0 Tohoku-oki earthquake provided a unique opportunity to investigate how the Japanese Islands' crust responds to instantaneous as well as transient stress changes due to the giant fault motion. This special issue includes 28 papers, which are the results of state-of-the-art researches carried out to understand the crustal dynamics and earthquake generation process in the island arc system. The papers might be categorized into several groups: (1) inhomogeneous structures related to earthquakes; (2) inelastic deformation; (3) stress and fault strength; (4) fluids and earthquakes; and (5) characteristic of fluids.

It is evident that inhomogeneous structures affect seismic activities, but the detail of the effect is still ambiguous. Baba and Yoshida (2020) clarified the detailed geological structure in the northeastern Japan forearc and demonstrated a close relationship between seismic activity and the geological structure of the overriding plate. Barbot (2020) constructed a two-dimensional rheological model for the northeastern Japan subduction zone. He showed that most of the partial ruptures of the megathrust are structurally controlled, and the model consistently explains the characteristics of historical earthquakes in the Miyagi segment, the slow-slip and foreshock preparatory phase of the 2011 Tohoku-oki

\footnotetext{
*Correspondence: toru.matsuzawa.c6@tohoku.ac.jp

${ }^{1}$ Graduate School of Science, Tohoku University, Sendai 980-8578, Japan Full list of author information is available at the end of the article
}

earthquake, the large slip near the trench during the giant rupture, and essential features of its postseismic deformation. Shi et al. (2020) modeled a representative crosssection of the Nankai subduction zone offshore Shikoku Island, where the frictional behavior is dictated by the structure and composition of the overriding plate. They showed that mechanical interactions between neighboring fault segments and the impact from the long-term viscoelastic flow strongly modulate the recurrence pattern of earthquakes and slow-slip events. Miyake and Noda (2019) investigated the effect of viscoelasticity on the transition between seismogenic and aseismic behavior using a numerical simulation. Their results indicate that the transition associated with slow-slip events and tremors is dominated by changes in frictional properties rather than changes in viscoelastic properties.

Not only the large-scale heterogeneity mentioned above, but local to regional scale inhomogeneities will also affect the seismogenesis. Hisakawa et al. (2020) investigated the rupture process of the 2018 Hokkaido Eastern Iburi earthquake, Japan, by using dynamic rupture simulations to show that the observed complexity of the event can be explained primarily by the effect of non-planar fault geometry with multiple bends. Tsuda et al. (2019) estimated the velocity structure in the Sanin district, southwestern Japan, using seismic travel-time tomography to find that the lower crust beneath the seismic belt showed lower velocities. They concluded that the seismic belt is generated because the lower crust beneath the belt is weak due to the high temperature in the eastern part and the water dehydrated from the Philippine Sea plate in the western part. Suemoto et al. (2020) 
derived a three-dimensional $\mathrm{S}$-wave velocity model for the San-in area of southwest Japan using ambient noise data from a dense seismic network. In the resulting model, faults and a previously unrecognized tectonic boundary appeared as low-velocity anomalies or velocity boundaries, and the velocity anomalies were also associated with many past earthquake hypocenters.

Since earthquakes release the elastic strain energy accumulated in the plates, elastic strain estimation is crucial to assess large earthquakes' potential. However, inelastic deformation is also essential to understand the topography and stress concentration, both of which are strongly related to earthquakes. Fukuda et al. (2020) investigated cooling/denudation history in the northern part of the northeastern Japan arc using thermochronometry. The results indicate slow denudation rates in the fore-arc side and high rates in the Ou Backbone Range and on the back-arc side, similar to the southern part of the arc. Fukahata et al. (2020) successfully separated plastic/viscous deformation from the observed strain in the northern Niigata-Kobe Tectonic Zone (NKTZ), central Japan, using GNSS data before and after the 2011 Tohoku-oki earthquake. Their results indicate that the strain rate was exceptionally faster before the Tohoku-oki earthquake because of plastic strain, and the discrepancy between the geodetic and geologic strain rates is much smaller in most of the period. Otsubo et al. (2020) investigated the relationship between contractional deformation of sedimentary mass in the upper crust and the geodetic strain rate in a high-strain zone of the mid-Niigata region, central Japan, to find numerous examples of layer-parallel slip (bedding-plane slip) generated by folding. The results support an existing model, based on geodetic observations, of mechanical decoupling between the weak sedimentary layers and basement. Dojo and Hiramatsu (2019) analyzed the temporal variation in coda $Q$ in the northeastern part of the NKTZ in central Japan. They found no statistically significant temporal variations in the spatial distribution of coda $\mathrm{Q}$ in the periods before and after the 2011 Tohoku-oki earthquake, which implies the existence of a persistent ductile deformation in the upper crust contributes essentially to the generation process of the high strain rate in the northeastern part of the NKTZ. Tamura et al. (2020) quantified the slip rate attributable to minor faults in the southeastern-central part of the NKTZ to the south of the Atotsugawa Fault, central Japan. Their results indicate that these minor faults contribute $4-24 \%$ of the total crustal strain in NKTZ. Meneses-Gutierrez and Nishimura (2020) analyzed GNSS data within the San-in Shear Zone, southwestern Japan, to clarify the width of the inelastic deformation zone in the lower crust beneath it. In eastern Tottori, the estimated inelastic zone's center coincides with the source region of the 1943 Tottori earthquake, while the inelastic zones are located just below the source regions of the 2000 Western and the 2016 Central Tottori earthquakes.

When an earthquake occurs, the shear stress on the fault must be larger than the strength. Thus, investigations of the stress concentration and strength reduction are essential to understand the earthquake generation process. Iio et al. (2020) investigated the temporal changes in the spatial distributions of hypocenters and focal mechanisms of aftershocks of the 2016 Central Tottori Prefecture earthquake, southwestern Japan, using the data from a dense temporary seismograph network. They concluded that the aftershock activity was controlled mainly by stress concentration rather than strength reduction due to high fluid pressure. Mitogawa and Nishimura (2020) calculated the temporal evolution of the Coulomb failure stress changes on the crustal faults in southwest Japan by utilizing viscoelastic modeling of megathrust earthquake cycles. They found that the large inland earthquakes before the megathrust earthquakes can be explained only when the apparent frictional coefficient is less than $\sim 0.1$. Kameda et al. (2019) demonstrated that the swelling pressure systematically increases with a decrease in sample porosity from experiments using the fault material, composed primarily of smectite, obtained by the IODP Expedition 343 JFAST program. The experiments suggest that the modified effective confining pressure of the fault is quite low or potentially zero, which means the fault may be intrinsically weak. In order to investigate the stress in the seismogenic zones, we need a great many focal mechanisms. Hara et al. (2019) developed a model of the convolutional neural networks (CNNs) to determine P-wave first-motion polarities of observed seismic waveforms automatically. They found that the accuracies of the CNN models were generally high $(\gtrsim 95 \%)$ and that regional dependence was insignificant.

Among all the possible causes of strength reduction, an increase in the pore fluid pressure is the most probable candidate. In and around many fault zones, Sibson (2020) found many geological and geophysical characteristics that support his "fault-valve" model, especially in compressional-transpressional tectonic regimes, which are better at containing overpressure and are 'load-strengthening' (mean stress rising with increasing shear stress). Maeda et al. (2019) investigated the focal mechanisms of aftershocks of the 2008 Iwate-Miyagi Nairiku earthquake (M 7.2) in the northeastern Japan arc and detailed Vp/Vs structure there. They concluded that exceptional N-S compressional aftershocks occurred in regions with low strength due to the high pore pressure and with $\mathrm{N}-\mathrm{S}$ compressional stress caused by the stress change due to the mainshock in a low differential 
stress regime. Matsumoto et al. (2020) investigated inelastic strain decay rates using aftershock moment tensor data obtained from dense seismic observations in the focal area of the 2000 M7.3 Western Tottori earthquake, southwestern Japan. They found an increase in the spatial variations in the inelastic strain rate, and they concluded that the decay in the inelastic strain rate is mainly controlled by a power-law fluid and slow decay in some regions might be attributed to aseismic slip. Amezawa et al. (2019) found distinct scattered wave packets (DSW) in the waveforms of S-coda from earthquakes around the Moriyoshi-zan volcano in the northeastern Japan arc. Since the DSW origin is located between the large cluster of earthquakes and a low-velocity zone, they concluded that the DSW origin was composed of geofluid accumulated midway in the upward fluid movement from the low-velocity zone to the earthquake cluster. Hutapea et al. (2020) developed a continuous monitoring system of the seismic velocity of the Japanese Islands using seismic interferometry. The system clearly shows spatiotemporal seismic velocity changes that could be related to pore pressure and/or magma variations.

As mentioned above, fluids can be the most responsible for reducing the fault strength. In order to model the strength reduction, however, we have to understand the detailed characteristics of fluids. Kusuhara et al. (2020) showed that the isotopic characteristics of brine samples from the Kashio mineral spring, central Japan, indicated that the Kashio brine could have originated from fluids dehydrated from the Philippine Sea slab as well as the Arima hot spring, located at $250 \mathrm{~km}$ west of the Kashio. They evaluated the chemical difference between those two springs with the depths of the subducting Philippine Sea slab and also possible interaction with crustal rocks above it. Koizumi et al. (2019) analyzed daily streamflow data collected in regions with strong ground motion during the 2016 Kumamoto earthquake. They concluded that the postseismic hydrological changes were caused mainly by earthquake-induced surface phenomena and little contribution from a hydrothermal fluid. Sato et al. (2020) investigated long-term hot spring discharge triggered by the $2011 \mathrm{Mw} 6.6$ Iwaki earthquake, northeastern Japan, and they concluded that such long-term discharge might be explained by the rise of thermal water from the deep part and the permeability changes along the hot spring channels. Fukuda and Shimizu (2019) investigated variation in water contents in quartz in the Sanbagawa Metamorphic Belt, Japan. Using an infrared spectroscopic mapping technique, they measured the quartz's water contents to be $40-310 \mathrm{ppm}$. The lowest values were obtained for large quartz grains in the high-grade metamorphic zones. They speculated that relatively high water contents in the lowest metamorphic grade zone reflect grain-boundary water. Kuwatani and Toriumi (2020) developed a kinetic model that illustrates the relative roles of intergranular diffusion and surface reactions in overall metamorphic net-transfer reactions involving solid solutions. Their conceptual model can be extended to capture more complex behaviors of metamorphic reactions in natural systems. Watanabe et al. (2019) conducted elastic wave velocity and electrical conductivity measurements in a brine-saturated granitic rock sample in the laboratory. Electron microscopic observation of pores in the sample showed remarkable variation in the aperture of each crack. At high pressures, narrow aperture parts are closed while wide aperture parts are still open to maintain conduction paths, explaining the variations in the seismic wave velocity and electrical conductivity observed in the field.

\section{Abbreviations}

CNN: Convolutional Neural Networks; DSW: Distinct scattered wave packets; GNSS: Global Navigation Satellite System; IODP: Integrated Ocean Drilling Program; JFAST: Japan trench FAST drilling project; NKTZ: Niigata-Kobe Tectonic Zone.

\section{Acknowledgements}

We express our sincere gratitude to the authors who contributed to this special issue and the reviewers who evaluated the contributions and gave thoughtful comments and suggestions. We also thank Editor-in-Chief Yasuo Ogawa and Vice Editor-in-Chief Masato Furuya for waiting patiently for our slow editing process.

\section{Authors' contributions}

All authors of this article are guest editors for this special issue. All authors read and approved the final manuscript.

\section{Funding}

This study was partly supported by the Ministry of Education, Culture, Sports, Science and Technology (MEXT) of Japan, under the Earthquake and Volcano Hazards Observation and Research Program, and KAKENHI Grant Numbers 26109001-26109007, and 15K21755.

\section{Competing interests}

The authors declare that they have no competing interests.

\section{Author details}

${ }^{1}$ Graduate School of Science, Tohoku University, Sendai 980-8578, Japan.

${ }^{2}$ Division of Earth and Planetary Sciences, Kyoto University, Kyoto 606-8502, Japan. ${ }^{3}$ Disaster Prevention Research Institute, Kyoto University, Uji 611-0011, Japan. ${ }^{4}$ Department of Earth Sciences, Faculty of Geosciences, Utrecht University, Utrecht 3584 CB, the Netherlands. ${ }^{5}$ Department of Earth and Planetary Sciences, School of Science, Tokyo Institute of Technology, Tokyo 152-8551, Japan. ${ }^{6}$ Department of Geoscience, Faculty of Science, Shizuoka University, Shizuoka 422-8529, Japan.

Received: 8 December 2020 Accepted: 9 December 2020 Published online: 01 February 2021

\section{References}

Amezawa Y, Kosuga M, Maeda T (2019) Temporal changes in the distinct scattered wave packets associated with earthquake swarm activity beneath the Moriyoshi-zan volcano, northeastern Japan. Earth Planets Space 71:132. https://doi.org/10.1186/s40623-019-1115-6 
Baba K, Yoshida T (2020) Geological structures controlled the rupture process of the 2011 M9.0 Tohoku-Oki earthquake in the Northeast Japan Arc. Earth Planets Space 72:94. https://doi.org/10.1186/s40623-020-01212-3

Barbot S (2020) Frictional and structural controls of seismic super-cycles at the Japan trench. Earth Planets Space 72:63. https://doi.org/10.1186/s4062 3-020-01185-3

Dojo M, Hiramatsu Y (2019) Temporal stability of coda Q in the northeastern part of an inland high strain rate zone, central Japan: implication of a persistent ductile deformation in the crust. Earth Planets Space 71:32. https://doi.org/10.1186/s40623-019-1013-y

Fukahata Y, Meneses-Gutierrez A, Sagiya T (2020) Detection of plastic strain using GNSS data of pre- and post-seismic deformation of the 2011 Tohoku-oki earthquake. Earth Planets Space 72:18. https://doi. org/10.1186/s40623-020-1144-1

Fukuda J, Shimizu I (2019) Water distribution in quartz schists of the Sanbagawa Metamorphic Belt, Japan: infrared spectroscopic mapping and comparison of the calibrations proposed for determining water contents. Earth Planets Space 71:136. https://doi.org/10.1186/s40623-019-1117-4

Fukuda S, Sueoka S, Kohn BP, Tagami T (2020) (U-Th)/He thermochronometric mapping across the northeast Japan Arc: towards understanding mountain building in an island-arc setting. Earth Planets Space 72:24. https:// doi.org/10.1186/s40623-020-01151-z

Hara S, Fukahata Y, lio Y (2019) P-wave first-motion polarity determination of waveform data in western Japan using deep learning. Earth Planets Space 71:127. https://doi.org/10.1186/s40623-019-1111-x

Hisakawa T, Ando R, Yano TE, Matsubara M (2020) Dynamic rupture simulation of 2018, Hokkaido Eastern Iburi earthquake: role of non-planar geometry. Earth Planets Space 72:36. https://doi.org/10.1186/s40623-020-01 160-y

Hutapea FL, Tsuj T, Ikeda T (2020) Real-time crustal monitoring system of Japanese Islands based on spatio-temporal seismic velocity variation. Earth Planets Space 72:19. https://doi.org/10.1186/s40623-020-1147-y

lio Y, Matsumoto S, Yamashita Y, Sakai S, Tomisaka K, Sawada M, lidaka T, Iwasaki T, Kamizono M, Katao H, Kato A, Kurashimo E, Teguri Y, Tsuda H, Ueno T (2020) Stationarity of aftershock activities of the 2016 Central Tottori Prefecture earthquake revealed by dense seismic observation. Earth Planets Space 72:42. https://doi.org/10.1186/s40623-020-01161-x

Kameda J, Uno M, Conin M, Ujiie K, Hamada Y, Kimura G (2019) Fault weakening caused by smectite swelling. Earth Planets Space 71:131. https://doi. org/10.1186/s40623-019-1108-5

Koizumi N, Minote S, Tanaka T, Mori A, Ajiki T, Sato T, Takahashi HA, Matsumoto N (2019) Hydrological changes after the 2016 Kumamoto earthquake. Japan Earth Planets Space 71:128. https://doi.org/10.1186/s4062 3-019-1110-y

Kusuhara F, Kazahaya K, Morikawa N, Yasuhara M, Tanaka H, Takahashi M, Tosaki Y (2020) Original composition and formation process of slab-derived deep brine from Kashio mineral spring in central Japan. Earth Planets Space 72:107. https://doi.org/10.1186/s40623-020-01225-y

Kuwatani T, Toriumi M (2020) Simple kinetic model for replacement reactions involving solid solutions: the significant role of geofluids. Earth Planets Space 72:8. https://doi.org/10.1186/s40623-020-1135-2

Maeda S, Matsuzawa T, Yoshida K, Okada T, Yoshida T (2019). Causes of the N-S compressional aftershocks of the E-W compressional 2008 Iwate-Miyagi Nairiku earthquake (M7.2) in the northeastern Japan arc. Earth Planets Space 71:94. https://doi.org/https://doi.org/10.1186/s40623-019-1073-z
Matsumoto S, lio Y, Sakai S, Kato A (2020) Inelastic strain in the hypocentral region of the 2000 Western Tottori earthquake (M 7.3) inferred from aftershock seismic moment tensors. Earth Planets Space 72:62. https:// doi.org/10.1186/s40623-020-01186-2

Meneses-Gutierrez A, Nishimura T (2020) Inelastic deformation zone in the lower crust for the San-in Shear Zone, Southwest Japan, as observed by a dense GNSS network. Earth Planets Space 72:10. https://doi.org/10.1186/ s40623-020-1138-z

Mitogawa T, Nishimura T (2020) Coulomb stress change on inland faults during megathrust earthquake cycle in southwest Japan. Earth Planets Space 72:66. https://doi.org/10.1186/s40623-020-01174-6

Miyake Y, Noda H (2019) Fully dynamic earthquake sequence simulation of a fault in a viscoelastic medium using a spectral boundary integral equation method: does interseismic stress relaxation promote aseismic transients? Earth Planets Space 71:137. https://doi.org/10.1186/s4062 3-019-1113-8

Otsubo M, Katayama I, Miyakawa A, Sagiya T (2020) Inelastic behavior and mechanical strength of the shallow upper crust controlled by layer-parallel slip in the high-strain zone of the Niigata region. Japan Earth Planets Space 72:30. https://doi.org/10.1186/s40623-020-01154-w

Sato T, Kazahaya K, Matsumoto N, Takahashi M (2020) Deep groundwater discharge after the 2011 Mw 66 Iwaki earthquake Japan. Earth Planets Space 72:54. https://doi.org/10.1186/s40623-020-01181-7

Shi Q, Barbot S, Wei S, Tapponnier P, Matsuzawa T, Shibazaki B (2020) Structural control and system-level behavior of the seismic cycle at the Nankai Trough. Earth Planets Space 72:27. https://doi.org/10.1186/s4062 3-020-1145-0

Sibson RH (2020) Preparation zones for large crustal earthquakes consequent on fault-valve action. Earth Planets Space 72:31. https://doi.org/10.1186/ s40623-020-01153-X

Suemoto Y, Ikeda T, Tsuji T, lio Y (2020) Identification of a nascent tectonic boundary in the San-in area, southwest Japan, using a 3D S-wave velocity structure obtained by ambient noise surface wave tomography. Earth Planets Space 72:15. https://doi.org/10.1186/s40623-020-1139-y

Tamura T, Oohashi K, Otsubo M, Miyakawa A, Niwa M (2020) Contribution to crustal strain accumulation of minor faults: a case study across the Niigata-Kobe Tectonic Zone. Japan Earth Planets Space 72:7. https://doi. org/10.1186/s40623-020-1132-5

Tsuda H, lio Y, Shibutani T (2019) Origin of the seismic belt in the San-in district, southwest Japan, inferred from the seismic velocity structure of the lower crust. Earth Planets Space 71:109. https://doi.org/10.1186/s4062 3-019-1091-x

Watanabe T, Makimura M, Kaiwa Y, Desbois G, Yoshida K, Michibayashi K (2019) Elastic wave velocity and electrical conductivity in a brine-saturated rock and microstructure of pores. Earth Planets Space 71:129. https://doi. org/10.1186/s40623-019-1112-9

\section{Publisher's Note}

Springer Nature remains neutral with regard to jurisdictional claims in published maps and institutional affiliations.

\section{Submit your manuscript to a SpringerOpen ${ }^{\odot}$ journal and benefit from:}

- Convenient online submission

- Rigorous peer review

- Open access: articles freely available online

- High visibility within the field

- Retaining the copyright to your article

Submit your next manuscript at $\boldsymbol{\nabla}$ springeropen.com 